\title{
EMOTRANS. LAS EMOCIONES Y EL TRANSMEDIA EN ADOLESCENTES ECUATORIANOS
}

EMOTRANS. EMOTIONS AND TRANSMEDIA IN ECUADORIAN ADOLESCENTS

Manuel Torres Mendoza, Ph.D.

Doctor en Comunicación Pública (España).

Docente-Investigador de la Universidad Internacional del Ecuador (UIDE), Ecuador. Director del proyecto Educación Transmedia Competencias transmedia y estrategias informales de aprendizaje de los adolescentes de la Universidad Nacional de educación de Educador (UNAE), Ecuador. matorresme@uide.edu.ec

María de los Ángeles Oliva Gimeno, Mgs. Magíster en Humanidades (España). Investigadora externa del proyecto Educación Transmedia Competencias transmedia y estrategias informales de aprendizaje de los adolescentes de la Universidad Nacional de Educación de Ecuador (UNAE), Ecuador. molivagim@uoc.edu

Andrea Ximena Castaño Sánchez, Ph.D. Doctora en Tecnología educativa: E-learning y Gestión del Conocimiento (Colombia). Docente-Investigadora del proyecto Educación Transmedia Competencias transmedia y estrategias informales de aprendizaje de los adolescentes de la Universidad Nacional de Educación de Ecuador (UNAE), Ecuador. andrea.castano@unae.edu.ec

\section{ARTÍCULO DE INVESTIGACIÓN}

Recibido: 28 de noviembre de 2018.

Aceptado: 18 de febrero de 2019.

\section{RESUMEN}

Se propone incorporar, en las planificaciones de aula, estrategias didácticas que desarrollen competencias ligadas a emociones y valores que se difunden en el entorno de consumo y producción digital de los adolescentes. La investigación se basa en una 
muestra que se llevó a cabo en escuelas de dos provincias de Ecuador utilizando la metodología short-term ethnography. Se identifican y analizan el discurso de las emociones, clasificadas por dispositivo o aplicación, aplicando la categoría de Actitud, a partir de la Teoría de la Valoración de Martin y White (2005). La categoría Actitud está relacionada tanto con respuestas emocionales como con sistemas de valores determinados por la cultura y se divide en tres subtipos: Afecto, Juicio y Apreciación. El Afecto se relaciona con evaluaciones ligadas a sentimientos y a emociones, el Juicio evalúa normas sociales y la conducta y la Apreciación está ligada a cuestiones estéticas, tanto de objetos como de procesos. Por último, se presenta una relación de contenidos curriculares que mejor se adaptan a la transmisión de valores y emociones en didácticas específicas. Como conclusión se debe constatar que el trabajo en clases ayuda a entender y gestionar las actitudes en función de la emoción, el juicio o la apreciación.

Palabras clave: alfabetización transmedia; adolescentes; Ecuador; educación; emociones.

\section{ABSTRACT}

It is proposed to incorporate, in the classroom plans, teaching strategies that develop competences linked to emotions and values that are disseminated in the environment of consumption and digital production of adolescents. The research is based on a sample that was carried out in schools in two provinces of Ecuador using the short-term ethnography methodology. The discourse of emotions is identified and analyzed, classified by device or application, applying the Attitude category, based on the Theory of Valuation of Martin and White (2005). The Attitude category is related to both emotional responses and value systems determined by culture and is divided into three subtypes: Affection, Judgment and Appreciation. Affect is related to evaluations linked to feelings and emotions, Judgment evaluates social norms and behavior and Appreciation is linked to aesthetic issues, both of objects and processes. Finally, a list of curricular contents that best adapt to the transmission of values and emotions in specific didactics is presented. In conclusion, it should be noted that class work helps to understand and manage attitudes based on emotion, judgment or appreciation.

Keywords: transmedia literacy; teenagers; Ecuador; education; emotions. 


\section{INTRODUCCIÓN}

Este trabajo es fruto del proyecto Educación Transmedia. Competencias transmedia y estrategias informales de aprendizaje de los adolescentes, que expande en Ecuador la línea de investigación desarrollada por los proyectos: Transalfabetismos (Ministerio de Economía y Competitividad de España, 2015-2017) y Transliteracy (Programa H2020 de la Unión Europea, 2015-2018), ambos dirigidos por Carlos A. Scolari desde la Universidad Pompeu Fabra de Barcelona. En este contexto, la UNAE pretende aportar los resultados de la investigación llevada a cabo en dos escuelas de la zona 6 (una en Azogues y la otra en Cuenca) con el fin de contrastarlos con otras realidades del mundo.

Los objetivos generales del proyecto son identificar las competencias transmedia y las estrategias informales de aprendizaje desarrolladas por los adolescentes fuera del ámbito escolar y diseñar una serie de actividades didácticas basadas en ellas. Estas habilidades en el aprendizaje informal abarcan desde la creación y distribución de contenidos en plataformas colaborativas de productos audiovisuales hasta la resolución de problemas en los videojuegos o la gestión de las redes sociales. La investigación analiza las prácticas informales para el aprendizaje en estudiantes de 12 a 17 años con diferentes situaciones sociales y geográficas en Ecuador, para lo cual se realizaron talleres en dos escuelas de las provincias de Azuay y Cañar de Ecuador, utilizando la metodología short-term ethnography. La información obtenida de dichos talleres se codificó a través del programa NvivoPro 11, que permite el análisis cualitativo de datos.

Analizar el discurso que los adolescentes y jóvenes intercambian en las redes sociales ayuda a desarrollar las competencias actitudinales que se requieren para desenvolverse de manera asertiva en el s XXI. Algunos modelos pedagógicos incorporan contenidos y procedimientos dirigidos a potenciar esta competencia, esencial para convivir en grupos heterogéneos y conseguir un escenario de aprendizaje adecuado a los usos actuales. En esta línea, la Universidad Nacional de Educación del Ecuador (UNAE) señala en sus ejes de trabajo (2015) que la incorporación de las TIC en la docencia no solo se debe atener a cuestiones tecnológicas, sino también a debatir de manera crítica los mensajes que se intercambian en espacios de comunicación intergrupal y en medios de masas. Estos últimos son los que más reflejan imágenes y narrativas que persiguen (y lo consiguen) llegar a determinados públicos y mantenerse entre las preferencias de los mismos. Por tanto, sobre estos puntos conviene llevar a cabo un análisis del discurso acerca de la opinión que tienen los adolescentes acerca de las prácticas que desarrollan

ISSN: 1390-9320, Vol. 6, No. 2, abril 2019 
y que nos muestran sus propias vidas como una extensión más de las narrativas transmedia.

Una de las teorías más pertinentes para categorizar la opinión es la teoría de la valoración, en inglés Appraisal Theory. Esta teoría consiste en la categorización de términos evaluativos en el texto. Según Kaplan, los términos evaluativos sirven para "evaluar, adoptar posiciones, construir personas textuales o identidades discursivas, asumir roles, negociar relaciones, y transformar en "naturales" las posturas intersubjetivas que son, en última instancia, ideológicas" (Kaplan, 2004, p. 53). Esta teoría surge a partir del trabajo de Martin y White (2005), entre otros autores, con aportaciones en lengua castellana de, por ejemplo, Bolívar (1994) y Kaplan (2004, 2007). Desde este punto de vista, la evaluación se concibe como una categoría expresiva que permite identificar la subjetividad implicada en los textos. Como indica Kaplan, la evaluación es una "dimensión semántico discursiva" (2007: 97) sobre los actores $\mathrm{y} / \mathrm{o}$ sus acciones.

\section{REVISIÓN TEÓRICA}

\section{Educar en la era tecnológica}

El concepto de alfabetización mediática fue protagonista, ya en los años 50 del siglo pasado, de algunos documentos publicados en Estados Unidos (Jolls y Wilson, 2014) Sobre este concepto, Len Masterman inició estudios pioneros en el ámbito anglosajón en su libro Teaching about Television en 1980 y el siguiente Teaching the Media en 1985, influenciado las teorías y modelos en los que se defiende una lectura crítica de los contenidos difundidos por los mass media. En fases posteriores, las investigaciones se han dirigido a enseñar a usar las tecnologías e incorporar los productos mediáticos en el contenido curricular. Lo importante ha sido poder analizar y evaluar críticamente los productos mediáticos o crear distintos tipos de contenidos a la manera en que lo hacían los mass media. El centro para el alfabetismo mediático (CML, Center for Media Literacy) difunde tres conceptos interrelacionados:

1. Media literacy is education for life in a global media world

2. The heart of media literacy is informed inquiry

3. Media literacy is an alternative to censoring, boycotting or blaming 'the media' 
Otros autores, como David Buckingham (2005), asignan un mayor protagonismo a los niños y adolescentes respecto del uso que hacen de medios de comunicación, como la televisión y el cine. Es decir, no están de acuerdo en el rol pasivo que desde posiciones más críticas se hace de este público y defienden una mayor investigación acerca de qué es lo que este público conoce acerca de los medios y cómo manejan su relación con estos. En el ámbito hispano, Joan Ferrés $(2005,2007,2015)$, entre otros, ha investigado aspectos de las competencias mediáticas a desarrollar en la educación obligatoria, siempre teniendo en cuenta los aspectos emocionales que son asimilados de manera más fácil que los contenidos racionales que se pretenden para el currículo escolar.

El mundo actual está sujeto a grandes cambios entre los que las nuevas tecnologías en la comunicación y el aprendizaje suponen un desafío que la educación no puede dejar a un lado. La alfabetización digital se presenta como una oportunidad para enseñar a los jóvenes a descifrar los mensajes y la información que les llega a través de la red (Almenara y Cejudo, 2008; Gutiérrez y Tayner, 2012; Levis 2006). Aprovechar las nuevas herramientas es el reto que los docentes deben aceptar como la manera de acercarse a los estudiantes para crear unas pedagogías horizontales adaptadas a la época actual. Como indican Aparici y García Marín: "Desarrollar un pensamiento crítico frente a los mensajes mediáticos, posibilitar un distanciamiento emocional ante la visión del mundo propuesta por los medios, estos sí son aspectos fundamentales de la MLE (media literacy education) y la educomunicación" (2017, p. 64). Así mismo Scolari, Winocur, Pereira y Barreneche, afirman que: "el alfabetismo transmedia interpela a los jóvenes en tanto prosumidores, creadores o distribuidores de contenidos mediáticos. En vez de estigmatizar esas nuevas prácticas mediáticas propone recuperarlas dentro del aula, pasando de lo informal a lo formal" (2018, p. 9)

La Web 2.0 ha transformado la forma de crear, consumir y distribuir la cultura, y el Transmedia ha ido un paso más allá convirtiendo, también, a muchos usuarios mediáticos en creadores de contenido: prosumidores. Sin embargo, aunque en la actualidad hay un interés fuertemente focalizado en estos prosumidores, es necesaria una ecología de interacciones entre los que crean y los que consumen lo que se crea, donde cada uno tiene una función que permite la otra. Sería la participación significativa de la que habla Jenkins: “...defendemos que incluso aquéllos que <<sólo>> leen, escuchan o miran lo hacen de forma distinta en el mundo de hoy: son conscientes de que pueden participar en diálogos más amplios sobre el contenido. No permanecen fuera de toda participación significativa" (Jenkins, Ford y Green, 2015, p. 179). Este compromiso considerado "pasivo" contribuye de una manera decisiva en la creación 
actual de la realidad, donde cada cual sabe que cualquier información puede ser comprobada y comparada e incluso puesta a debate a través de la red.

Yochai Benkler nos habla de la importancia de las plataformas digitales en la sociedad contemporánea a propósito de su contribución a crear sujetos con actitudes más activas ante la realidad social:

Dichas plataformas permiten que cualquiera, en cualquier sitio, atraviese su vida práctica observando el entorno social con nuevos ojos —los ojos de alguien que realmente podría introducir una reflexión, una crítica o una inquietud en el debate público. De este modo los individuos se vuelven observadores sociales menos pasivos y, por consiguiente, más comprometidos y potencialmente capaces de convertirse en sujetos del debate político; se vuelven participantes más comprometidos en los debates acerca de sus observaciones. (2015, p. 45)

Los usuarios (entre ellos los estudiantes) se han convertido activos, son ellos los que salen a buscar información, lo que favorece la creación de múltiples contenidos que a su vez están expuestos a su juicio, a su apropiación y evolución, contribuyendo de este modo en la realización de sus propias identidades. Esto hace que la cultura en la que vivimos se convierta como nos dice Benkler en: "algo más propio de lo que permitía la cultura de los medios masivos. A partir de estas consideraciones, podemos afirmar que la cultura se democratiza cada vez más: se vuelve autorreflexiva y participativa" (2015, p. 49).

La inteligencia compartida que se produce a través de la red supone una construcción social de la información que favorece una democratización de la misma (Guitart, 2012; Lévy, 1994; Ribes, 2007; Valero, 2004). Al mismo tiempo, la información llega en exceso a unos jóvenes que se están formando tanto personal como académicamente y, a menudo, internet es visto más como una amenaza por padres y educadores que como una herramienta útil para el aprendizaje. La solución a este problema podría ser una correcta educación mediática que pueda ayudar a estos jóvenes a saber seleccionar y aprovechar el material accesible en los espacios virtuales y convertirlo en información útil y constructiva en este proceso. La alfabetización transmedia debería ser el instrumento para saber evaluar de manera crítica todo el material que a través de la red llega a ellos y asegurar de este modo su buen uso e integración en el entorno educativo. 
Área y Pessoa describen "la Web 2.0 como la biblioteca universal, como mercado global, como un puzle gigante de hipertextos, como una plaza pública de comunicación e interacción social, como un territorio de expresión multimedia y audiovisual, y como múltiples entornos virtuales interactivos" (2012, p.14), a través de esta investigación se quiere ver también como una plataforma que es parte de la cotidianidad de los adolescentes y que por lo tanto se debe integrar en su educación y aprendizaje formal aprovechando el potencial que supone.

Los nuevos sistemas educativos saben que una de las claves para un buen aprendizaje es la educación personalizada, pero esto resulta, a nivel general, insostenible tanto a nivel logístico como económico. El conocido consultor educativo Curtis Johnson ve en la tecnología la herramienta para que este objetivo sea logrado, ya que donde la escuela no puede llegar a atender particularmente a cada estudiante, la red puede ofrecerle lo que necesita de manera personalizada, en el momento y lugar que le resulten más cómodos, suponiendo de este modo el complemento perfecto que necesita el aprendizaje en la época actual (Christensen, Johnson \& Horn, 2008).

\section{Categorizar las emociones}

La teoría de la valoración distingue tres categorías: la Actitud, el Compromiso y la Gradación. La Gradación analiza en una escala la intensidad y la fuerza de los enunciados, mientras que el Compromiso se refiere a la voz -monofonía o polifonía en el texto- de los autores. La Gradación queda descartada puesto que ubica la evaluación en una escala de intensidad, mostrando un rango entre los calificativos que pueden ser evaluados de manera distinta según la propia escala del receptor. Este hecho podría dar una excesiva interpretación por parte del analista de las opiniones, por lo que se suprimen del análisis ya que podría ofrecer un margen de error elevado en la categorización. En cuanto al Compromiso, categoría que identifica la monofonía o polifonía en el texto, es una herramienta que clasifica e identifica las ocasiones en el que el diario habla por sí mismo o traslada la autoría a otros sujetos del discurso, como pueden ser las personas o entes abstractos que aglutinan identidades colectivas 0 valores compartidos. Estas dos últimas categorías no forman parte del análisis de esta tesis, dado que lo que interesa conocer es la ideología, claramente ligada a la Actitud.

La categoría Actitud está relacionada tanto con respuestas emocionales como con sistemas de valores determinados por la cultura. Esta categoría se divide en tres subtipos: Afecto, Juicio y Apreciación. El Afecto se relaciona con las evaluaciones 
ligadas a los sentimientos y a las emociones, el Juicio evalúa las normas sociales y la conducta y, por último, la Apreciación está ligada a cuestiones estéticas, tanto de objetos como de procesos (Kaplan, 2007. p. 101-102). Merece especial atención en esta investigación el Afecto para conocer las emociones. A continuación, se describen esta subcategoría de la Actitud.

\section{Afecto}

El Afecto es un "tipo de evaluación lingüística mediante la cual los emisores señalan cuál es su posición emocional hacia las personas, las cosas, las situaciones o los eventos; o reportan las respuestas emocionales de terceros" (Kaplan, 2007, p. 104-105). Por lo tanto, el Afecto se puede entender como una de las partes de un sistema que según Martin y White: "involves three semantic regions covering what is traditionally referred to as emotion, ethics and aesthetics" (2005, p. 62). Estas emociones pueden ser de carácter negativo o positivo "de acuerdo con criterios popularmente aceptados en la cultura occidental" (Kaplan, 2007, p.105) y se clasifican en felicidad, seguridad y satisfacción, categorías que Kaplan denomina realis, que se fundamentan en situaciones presentes. En cambio, cuando los sentimientos tienen que ver con situaciones futuras y se relacionan con el deseo o el miedo, las denomina irrealis.

El Afecto puede expresarse como una cualidad, es decir, como un atributo o una circunstancia, o como un proceso mental o conductual. En cuanto a los indicadores lingüísticos del Afecto, estos son verbos de emoción, como, por ejemplo, 'amar'/'odiar'; adverbios de modo, como 'alegremente'/'tristemente', adjetivos, como 'feliz'/'triste', y nominalizaciones del tipo 'alegría'/'desesperación' (Kaplan, 2007, p.106). Los indicadores lingüísticos también se dividen en autorales, como por ejemplo, 'amo a los niños', y no autorales, cuyo ejemplo sería: 'la población ama a los niños' (Kaplan, 2007, p.106). Para apreciar una imagen de las categorías y subcategorías que componen la Actitud en el siguiente gráfico (1) se presenta el esquema de las categorías. 


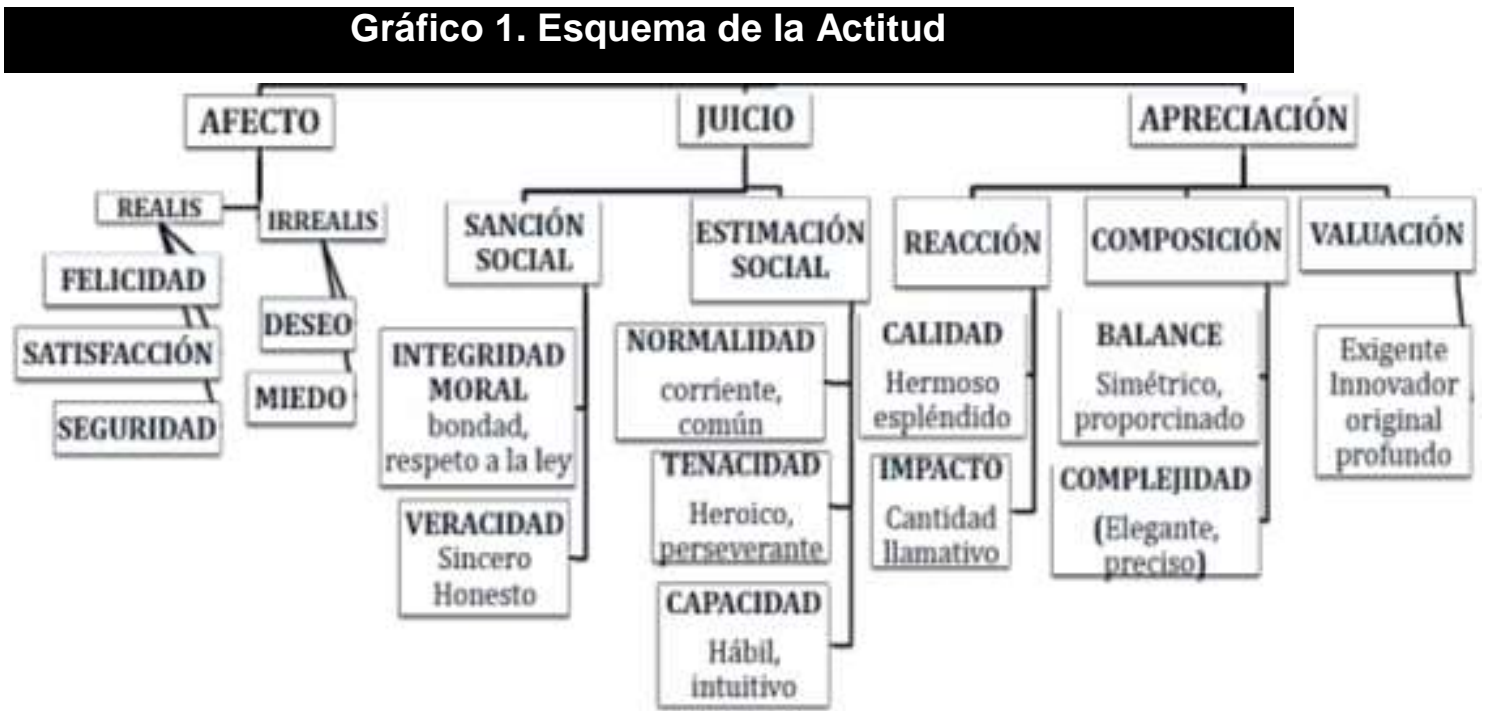

Fuente: Elaboración propia a partir de Kaplan (2004) y Martin y White (2005).

\section{MATERIALES Y MÉTODOS}

\section{Realidad en la zona de planificación 6 de Ecuador}

La zona de planificación 6 de Ecuador está compuesta por las regiones de: Cañar, Azuay y Morona Santiago. Este estudio se ha centrado en Cañar y Azuay y en las poblaciones de Azogues y Cuenca que representan los cantones más poblados de sus respectivas provincias.

Según el último censo real de 2010, Cuenca tiene un total de 505.585 habitantes, de los cuales 329.928 con un $65,3 \%$ de su totalidad pertenecen al área urbana y 175.657 con un $34,7 \%$ ocupan el área rural, con un pronóstico de crecimiento hasta 603.269 habitantes en 2017. Azogues tiene un total de 70.064 habitantes, de los cuales 33.848 pertenecen al área urbana que ocupa el $48 \%$ de su territorio y 36.216 se ubica en su área rural que ocupa el 51,7\% del mismo. Se hace un pronóstico de crecimiento hasta 82.497 habitantes para 2017 (SENPLADES, 2015).

La migración, en su mayoría de carácter internacional, causada por diversos factores socio-económicos, como la falta de recursos, de trabajo, de servicios públicos y sobre todo la perspectiva de mejorar la vida familiar, ha hecho cambios en la composición familiar debido a la movilización del padre o la madre de familia. Esto ha acentuado la influencia de su también cultura occidental que convive con una fuerte tradición de la cultura andina en los jóvenes de la zona.

ISSN: 1390-9320, Vol. 6, No. 2, abril 2019 
Otros de los factores a tener en cuenta son los relativos a la calidad de la enseñanza. Esta puede ser medida a partir de los resultados que arrojan las evaluaciones del INEVAL en la que periódicamente tanto estudiantes, como bachilleres y docentes son sometidos a pruebas, tanto de contenido, como de competencias y didácticas. En los resultados de Ser Maestro de 2016, tanto la provincia de Azuay y Cañar en general como las ciudades de Cuenca y Azogues, en particular, no superan en su promedio el 700 de calificación media. Los promedios son en Azuay. 677,1, Cañar: 664,7, Cuenca: 682,3 y Azogues: 670,4. (INEVAL, 2016).

Otros datos importantes a tener en cuenta es el que obtienen los estudiantes en la prueba de Ser Bachiller, que es la que les otorga el acceso a las Universidades. En este sentido, se puede apreciar que, en los resultados de 2017, en promedio, en las ciudades se obtienen porcentajes superiores a los obtenidos en la provincia (rural). En Azuay: 703,8 (puntos sobre 1.000); Cañar: 709,7, Cuenca: 714,7 y Azogues: 719,8 (INEVAL, 2017) Sin duda, el hecho de ser la capital puede ser uno de los factores, ya que les habilitaría para acceder a mejores conexiones, así como a servicios de bibliotecas, etc.

\section{Técnicas y método}

La muestra se ha llevado a cabo en dos escuelas, de las cuales han participado 136 estudiantes de los niveles: 8ํㅜ de EGB y 3aㅡ de BGU. Para la selección de estas escuelas se ha tenido en cuenta que son representativas en cuanto a la demografía de la región, pero también responden a perfiles diferenciados en función de su ubicación (rural o urbana) y de su financiamiento (público o privado) así como de cuestiones relativas a escoger una muestra representativa y diversa. Se ha utilizando la metodología shortterm ethnography y la información obtenida de la investigación se ha codificado a través del programa NvivoPro 11, que permite el análisis cualitativo de datos y la investigación se encuentra en fase de la explotación de los mismos a través de este software.

El siguiente cuadro muestra las técnicas utilizadas para la recogida de datos en las diferentes unidades educativas que han participado en la muestra:

Tabla 3. Técnicas utilizadas en la recolección de datos.

\begin{tabular}{|l|l|}
\hline Técnica & Descripción \\
\hline
\end{tabular}




\begin{tabular}{|c|c|}
\hline $\begin{array}{l}\text { Observación de } \\
\text { participantes }\end{array}$ & $\begin{array}{l}\text { Se ha utilizado en las diferentes etapas de la investigación, tanto } \\
\text { en línea como fuera de línea, para obtener un conocimiento } \\
\text { directo y experiencial de las comunidades seleccionadas para el } \\
\text { estudio. Sirve para conocer la sociabilidad, los valores } \\
\text { compartidos y las formas de organización de los adolescentes en } \\
\text { red. }\end{array}$ \\
\hline Cuestionarios & $\begin{array}{l}\text { Los cuestionarios -ya sea en línea o presenciales- han sido útiles } \\
\text { para mapear las características sociológicas y demográficas de } \\
\text { los adolescentes que participan en el estudio. }\end{array}$ \\
\hline Talleres & $\begin{array}{l}\text { Los talleres se consideran como una instancia intermedia de } \\
\text { recolección de datos entre los cuestionarios (de carácter general) } \\
\text { y las entrevistas individuales en profundidad. A través de los } \\
\text { talleres - ya sean orientados a los videojuegos o la narrativa- se } \\
\text { han obtenido datos sobre valores compartidos, adquisición de } \\
\text { competencias y estrategias grupales de aprendizaje en línea, } \\
\text { procesos de creación, resolución de problemas, etc. El equipo ha } \\
\text { realizado } 2 \text { talleres en cada unidad educativa y en cada nivel que } \\
\text { participa en la investigación (Total: } 8 \text { grupos). Los talleres han } \\
\text { tenido un carácter lúdico-creativo y se han basado en técnicas de } \\
\text { gamestorming (Gray, Brown y Macanufo, 2012) y otras } \\
\text { actividades participativas destinadas a facilitar los intercambios } \\
\text { con los adolescentes. }\end{array}$ \\
\hline $\begin{array}{l}\text { Entrevistas } \\
\text { individuales } \\
\text { en profundidad }\end{array}$ & $\begin{array}{l}\text { Las entrevistas con actores relevantes detectados en las fases } \\
\text { anteriores han facilitado la comprensión de aspectos como las } \\
\text { estrategias individuales de aprendizaje en línea o acceder a } \\
\text { narraciones acerca de sus propias experiencias. Estas } \\
\text { entrevistas incluyen historias de vida y tienen un carácter } \\
\text { autobiográfico respecto a las prácticas mediáticas. }\end{array}$ \\
\hline $\begin{array}{l}\text { Diarios de uso y } \\
\text { consumo } \\
\text { mediático }\end{array}$ & $\begin{array}{l}\text { Estos diarios se han realizado con la intención de ser utilizados } \\
\text { de manera complementaria para ampliar la información obtenida } \\
\text { a través de los talleres y entrevistas. }\end{array}$ \\
\hline
\end{tabular}

Fuente: elaboración propia a partir de la investigación realizada.

La investigación ha contado con diversas actividades participativas, tanto previas como durante la realización del trabajo de campo que quedan reflejadas en la siguiente tabla: 
Tabla 4. Actividades participativas del trabajo de campo.

\begin{tabular}{|c|c|c|c|}
\hline $\begin{array}{c}\text { Eventos de } \\
\text { participación }\end{array}$ & Número & Lugar & Participantes \\
\hline \multirow{2}{*}{$\begin{array}{l}\text { Sesión de } \\
\text { información para } \\
\text { el consentimiento } \\
\text { de padres }\end{array}$} & 2 & $\begin{array}{l}\text { Unidad } \\
\text { Educativa } \\
\text { Luis Cordero } \\
\text { Azogues }\end{array}$ & \multirow[t]{2}{*}{136} \\
\hline & & $\begin{array}{l}\text { Unidad } \\
\text { Educativa } \\
\text { Técnico } \\
\text { Salesiano } \\
\text { Cuenca }\end{array}$ & \\
\hline \multirow{2}{*}{$\begin{array}{l}\text { Sesión de } \\
\text { información para } \\
\text { el consentimiento } \\
\text { de estudiantes }\end{array}$} & 2 & $\begin{array}{l}\text { Unidad } \\
\text { Educativa } \\
\text { Luis Cordero } \\
\text { Azogues }\end{array}$ & \multirow[t]{2}{*}{142} \\
\hline & & $\begin{array}{l}\text { Unidad } \\
\text { Educativa } \\
\text { Técnico } \\
\text { Salesiano } \\
\text { Cuenca }\end{array}$ & \\
\hline \multirow[t]{2}{*}{$\begin{array}{l}\text { Encuesta de usos } \\
\text { mediáticos de los } \\
\text { estudiantes }\end{array}$} & 1 & $\begin{array}{l}\text { Unidad } \\
\text { Educativa } \\
\text { Luis Cordero } \\
\text { Azogues }\end{array}$ & \multirow[t]{2}{*}{136} \\
\hline & & $\begin{array}{l}\text { Unidad } \\
\text { Educativa } \\
\text { Técnico } \\
\text { Salesiano } \\
\text { Cuenca }\end{array}$ & \\
\hline $\begin{array}{l}\text { Taller de Cultura } \\
\text { Participativa }\end{array}$ & 4 & $\begin{array}{l}\text { Unidad } \\
\text { Educativa } \\
\text { Luis Cordero } \\
\text { Azogues }\end{array}$ & 74 \\
\hline
\end{tabular}

ISSN: 1390-9320, Vol. 6, No. 2, abril 2019 


\begin{tabular}{|c|c|c|c|}
\hline & & $\begin{array}{l}\text { Unidad } \\
\text { Educativa } \\
\text { Técnico } \\
\text { Salesiano } \\
\text { Cuenca }\end{array}$ & \\
\hline \multirow[t]{2}{*}{$\begin{array}{l}\text { Taller de } \\
\text { videojuego }\end{array}$} & \multirow[t]{2}{*}{4} & $\begin{array}{l}\text { Unidad } \\
\text { Educativa } \\
\text { Luis Cordero } \\
\text { Azogues }\end{array}$ & \multirow[t]{2}{*}{62} \\
\hline & & $\begin{array}{l}\text { Unidad } \\
\text { Educativa } \\
\text { Técnico } \\
\text { Salesiano } \\
\text { Cuenca }\end{array}$ & \\
\hline $\begin{array}{l}\text { Diarios de uso y } \\
\text { consumo } \\
\text { mediático }\end{array}$ & 19 & $\begin{array}{l}\text { Unidad } \\
\text { Educativa } \\
\text { Luis Cordero } \\
\text { Azogues } \\
\text { Unidad educativa } \\
\text { Técnico } \\
\text { Salesiano } \\
\text { Cuenca }\end{array}$ & 19 \\
\hline \multirow[t]{2}{*}{$\begin{array}{l}\text { Entrevistas } \\
\text { personales }\end{array}$} & \multirow[t]{2}{*}{19} & $\begin{array}{l}\text { Unidad } \\
\text { Educativa } \\
\text { Luis Cordero } \\
\text { Azogues }\end{array}$ & \multirow[t]{2}{*}{19} \\
\hline & & $\begin{array}{l}\text { Unidad } \\
\text { Educativa } \\
\text { Técnico } \\
\text { Salesiano } \\
\text { Cuenca }\end{array}$ & \\
\hline
\end{tabular}

Fuente: elaboración propia a partir de la investigación realizada.

A través de todas estas herramientas la investigación pretende crear un puente para acercar las prácticas educativas formales a la realidad cotidiana de miles de adolescentes inmersos en las redes sociales y la comunicación digital interactiva y 
contribuir a romper la barrera que existe entre los docentes y estudiantes en lo referente al consumo mediático con el fin de potenciar una enseñanza más horizontal adecuada a nuestro tiempo.

\section{ANÁLISIS DE RESULTADOS}

De las 19 entrevistas realizadas a los estudiantes más activos de los talleres de cultura participativa se han seleccionado ocho (el 42\%). Estas entrevistas estaban estructuradas a partir de la codificación que desde el proyecto Transmedialiteracy se planificó con el fin de que se puedan contrastar las realidades de diversos lugares del mundo. Es así que los nodos de las categorías principales (Tabla 5) reflejan el número de codificaciones que han tenido las 8 entrevistas. Hay que recordar que en ocasiones un mismo enunciado puede estar categorizado en distintos nodos, ya que las subcategorías anidadas precisan las categorías exactas a las que se puede atribuir cada enunciado o unidad de sentido.

Tabla 5. Nodos de codificación.

\begin{tabular}{|l|r|}
\hline Nodo & rodificaciones \\
\hline 1. ¿Qué haces? & 648 \\
\hline 2. ¿Con qué? & 177 \\
\hline 3. ¿Cómo lo haces? & 3 \\
\hline 4. ¿Por qué lo haces? & 47 \\
\hline 5. ¿Cómo aprendiste a hacerlo? & 61 \\
\hline 6. Otros & 65 \\
\hline Total & $\mathbf{1 0 0 1}$ \\
\hline
\end{tabular}

Fuente: elaboración propia a partir de la explotación de la base de datos.

La mayor parte de las codificaciones han recaído sobre la categoría de ¿Qué es lo que haces? (¿What do you do?) la cual aglutina 648 codificaciones de las 1001 en total que tienen estas 8 entrevistas. Es destacado el número de codificaciones que ha adquirido el nodo y que se ajusta a los usos que los estudiantes de las escuelas que en el estudio de caso han participado de los talleres. Así, existe todavía una clara preponderancia de cuestiones ligadas al ocio que se despliega en las redes sociales, sobre todo utilizando la tecnología que lidera los usos de las personas en el mundo: el celular. No obstante, estos primeros datos es conveniente que se profundice aún más en las preferencias de estos estudiantes, quienes, a pesar de no pertenecer a una muestra representativa, sí que pueden dar indicadores válidos para proyectar algunas ideas. Por tanto, hay que 
tener en cuenta, que este nodo a su vez posee algunas categorías anidadas bajo el mismo, entre las que se encuentran las siguientes (Tabla 6).

\begin{tabular}{|l|r|}
\hline \multicolumn{2}{|c|}{ Tabla 6. Subnodos de 20. nivel de la categoria: ¿Qué haces? } \\
\hline Subnodo & Codificaciones \\
\hline 1.1. Mirar, ver, escuchar & 409 \\
\hline 1.2. Jugar & 27 \\
\hline 1.3. Leer & 25 \\
\hline 1.4. Crear, hacer, remezclar & 56 \\
\hline 1.5. Participación en redes sociales & 127 \\
\hline 1.6. Asistir & 0 \\
\hline 1.7. Performance & 2 \\
\hline 1.8. Otros & 2 \\
\hline
\end{tabular}

Fuente: elaboración propia a partir de la explotación de la base de datos

Como se puede apreciar en la tabla anterior, el primer subnodo (1.1) es el que aglutina la mayoría de codificaciones (409). Esta situación da cuenta de que aún existe una gran pasividad de receptor entre los estudiantes. No obstante, la interacción que permiten las redes sociales se ve reducida a comentarios y dar "me gusta" a las fotografías, tanto de amigos como de celebridades del mundo online. Es por ello que la segunda categoría cuantitativamente es la de participación en redes sociales, la cual aglutina 127 codificaciones de las 8 entrevistas.

Dentro de la categoría 1.1 se agrupan a su vez otras categorías que especifican cuál es la actividad preferida de los estudiantes y cuyos gustos se dividen principalmente entre las series y las películas, seguidas del acceso a videos en YouTube (Tabla 7).

Tabla 7. Subnodos de 3er. nivel de categoría: ¿Qué haces?

\begin{tabular}{|l|r|}
\hline \multicolumn{2}{|c|}{ Tabla 7. Subnodos de 3er. nivel de categoría: ¿Qué haces? } \\
\hline Nodo & Codificaciones \\
\hline 1.1.1. Películas & 157 \\
\hline 1.1.2. Series & 114 \\
\hline 1.1.3. Youtubers & 71 \\
\hline 1.1.4. Famosos & 31 \\
\hline
\end{tabular}

ISSN: 1390-9320, Vol. 6, No. 2, abril 2019 


\begin{tabular}{|l|r|}
\hline 1.1.5. Música & 19 \\
\hline 1.1.6. Programas de televisión y radio (realities, talkshows...) & 4 \\
\hline 1.1.7. Información y publicidad & 10 \\
\hline
\end{tabular}

Fuente: Elaboración propia a partir de la explotación de la base de datos

Como se puede apreciar en la tabla anterior (7) la televisión y los programas de radios ocupan muy poco tiempo de la dieta mediática de los estudiantes de la muestra. Esto confirma que la atención disponible se dirige a aquellos contenidos compartidos en las redes sociales, cuyos principales usuarios suelen tener vínculos de afinidades emocionales (ya sea por parentesco, amistad o compañerismo).

\section{Discusión}

\subsection{Las emociones para el aprendizaje}

La investigación: "Educación Transmedia: Competencias transmedia y estrategias informales de aprendizaje de los adolescentes" ha comprobado cómo los jóvenes se expresan y edifican personalmente, en base a las teorías de la Actitud descritas más arriba, y teniendo en cuenta que viven una realidad dominada por la tecnología y por la imagen.

Desde el punto de vista académico siempre se han visto con preocupación los aparatos o las tecnologías que usan los niños, adolescentes y jóvenes. No se ha tenido en cuenta, como afirma Rossana Reguillo que lo más importante es "entender que la relevancia del «aparato», de la técnica, del medio, no radicaba en su propia especificidad, sino en su capacidad de potenciar nuevos imaginarios, nuevas formas de sentir y pensar. Nuevos estatutos cognitivos que trastocaban la experiencia" (2017, p. 219). Este estatuto cognitivo al que hace mención Reguillo deviene de los derroteros que transitan las narrativas en las que, sobre todo, los más jóvenes suelen adentrarse. Conviene que los investigadores esquiven el fetiche al aparato tecnológico y dirigir el foco hacia las posibilidades que ofrece la capacidad de atracción que ejercen las redes sociales en el s. XXI.

Vivimos en la era de las imágenes. Por eso es de vital importancia una buena educación mediática que enseñe a seleccionar mensajes visuales y a canalizar las emociones desatadas con respecto a éstos. El desarrollo tecnológico ha situado al lenguaje visual como la madre de todos los lenguajes que nutre buena parte de la cognición juvenil. En

ISSN: 1390-9320, Vol. 6, No. 2, abril 2019 
una de las entrevistas mantenidas con uno de los estudiantes que participó en nuestra investigación, el chico de 17 años confesó que había elegido la especialidad de mecatrónica en el bachillerato después de quedar impresionado al ver la película de Iron Man:

(...) yo entré a mecatrónica porque vi una película... Iron Man, por eso entré en mecatrónica. Me fue bien y me sigue yendo bien, tengo buenas notas, pero como que ya me dejó de gustar tanto, entonces por eso me voy a medicina...pero ver la película en vacaciones... tenía que decidir en las carreras que había aquí, entonces decidí entrar en mecatrónica (Alias Iron Man. Entrevista personal N`3. 24 de abril de 2017)

Sin embargo, el entrevistado, reconocía que habría sido mejor coger otra especialidad que lo preparase para estudiar la carrera universitaria de medicina, la que realmente le acabó motivando. Pero la impresión y el impacto que causaron unas imágenes en un momento determinado de su adolescencia le hicieron elegir en base a una ilusión provocada por las emociones experimentadas al ver una película, a montar una hiperrealidad, una realidad construida "no real" que puede llegar a superar la realidad misma como ya visionó Baudrillard (1978) en su momento. Del mismo modo que las palabras transforman la realidad, "el lenguaje visual también tiene este poder transformador de lo real, y nunca ha sido tan potente como hoy en día" (Acaso y Megías, 2017 , p. 27). En el momento en que vivimos Afecto y Apreciación se entremezclan afectando al Juicio, en esa invasión de imágenes que irrumpen nuestra cotidianidad en diversos ámbitos.

Joan Fontcuberta (2016) hace una larga reflexión en su último libro sobre las imágenes en la actualidad y el modo en que invaden y afectan nuestras vidas: "habitamos la imagen y la imagen nos habita" (2016, p. 9). Este nivel de transformación que pueden tener las imágenes sobre nosotros nos indica la urgencia de una educomunicación adecuada, que enseñe a mirarlas con una visión crítica que vaya más allá de si algo nos gusta o no, más allá de una mera manera de mirar contemplativa y estética.

No obstante, el deseo sigue estando fuertemente condicionado por el entorno, la cultura, la familia, la sociedad. Otro de los entrevistados, también de 17 años y amante del mundo anime, comentaba que a veces le gustaría caracterizarse como alguno de sus personajes favoritos pero que: "Cuenca es muy cerrada, es muy conservadora. No hay como salir, como en otros lados, salir vestido con una túnica y salir a la calle...Es como decir: mírenme soy..." por lo que se abstenía de lo que le desearía hacer por temor a la 
reacción de su entorno, por el miedo a la sanción social (Alias Manga. Entrevista personal $N^{\circ} 4.24$ de abril de 2017).

Estos son ejemplos de cómo las propias vidas de los estudiantes se convierten en una extensión de las narrativas transmedia, que siguen la estela que crean los jóvenes, como desarrolladores (portadores) del mensaje del futuro, en el que las convenciones o el apego a las tradiciones van cediendo para dejar paso a una nueva forma de entender la cultura, las relaciones y la visión que se tiene de lo que deberían hacer. En palabras de Reguillo:

La importancia que Mead atribuía las tres formas de culturas que coexistían no de manera pura - en las sociedades: la postfigurativa, en [SIC] dicho de manera simple, los niños aprenden de los abuelos; la cofigurativa, en la que los jóvenes aprenden de sus pares y, la prefigurativa, la más radical, en la que los más jóvenes asumen el papel de maestros e intérpretes en un mundo que nace. (2017, p. 219)

Esta etapa prefigurativa en la que nos encontramos demanda que quienes sean protagonistas (la juventud) decidan cuáles son los aspectos de la cultura legada que les interesa mantener y cuáles los que quisieran cambiar. Esta nueva situación, como ontología del aprendizaje, reclama de los adultos no una aceptación pasiva y acrítica, sino una colaboración para señalar de manera franca los aspectos más críticos sobre los que nos ha tocado ser protagonistas.

La neurociencia lleva años apuntando que utilizar herramientas que emocionen al alumno en el aula es el secreto para un buen aprendizaje tanto teórico como práctico. Damasio (2006) propone que razón y emoción necesitan de una complementación mutua ya que después de estudiar a pacientes que habían perdido la capacidad de emocionar y sentir en determinadas circunstancias comprobó que tenían importantes deficiencias en su capacidad para tomar decisiones y, por tanto, que la racionalidad estaba directamente ligada a las emociones. Además, estos pacientes tenían también dificultades para la socialización, por lo que se deduce de sus estudios que circuitos cerebrales que se ocupan conjuntamente de las emociones y de la toma de decisiones participarían en la gestión cognitiva y en la conducta social.

Es una realidad que los jóvenes se emocionan a través de sus prácticas mediáticas. Videojuegos, series, películas, redes sociales.... acaparan una gran parte de su tiempo por este motivo. Aprovechar los conocimientos mediáticos de nuestros jóvenes, que 
influyen sobre sus vidas de manera significativa, puede ser una manera de llegar a la motivación que necesitan para fomentar las ganas de aprender en la educación formal.

\section{CONCLUSIONES}

Desde un punto de vista discursivo se pueden identificar emociones, juicios o apreciaciones a partir del análisis cualitativo que el docente aplique a los contenidos generados por sus estudiantes. Esta tarea requiere de una relación horizontal entre educadores y educandos, basada en una relación bidireccional que fomente esa generación de contenidos por parte de los estudiantes.

La importancia de reconocer los valores y las emociones que transmiten las narraciones audiovisuales es destacada por autores como Aierbe-Barandiaran, A. y OreguiGonzález, E. (2016) para quienes desde antes de la adolescencia los niños y niñas son sometidos a una "amplia gama de valores éticos y competenciales, sobre todo valores vitales, mientras los valores estéticos y trascendentales apenas son representados" (p.77). En el caso de los jóvenes, también merecen una correcta educación mediática que pueda ayudarlos a saber seleccionar y aprovechar el material accesible en los espacios virtuales y convertirlo en información útil y constructiva en su proceso de formación y crecimiento académico y personal.

Las prácticas mediáticas de los jóvenes nos dan pistas valiosas sobre los derroteros de la construcción de sus identidades, de sus fortalezas y debilidades. Los docentes tienen la obligación de estar atentos y tener en cuenta esa realidad para poder orientar y formar críticamente a los estudiantes. Como nos dicen Ferrés y Piscitelli:

Habrá que considerar insuficiente una educación mediática que no atienda a la dimensión emocional de las personas que interaccionan con las pantallas, porque hoy sabemos que la razón - y, en consecuencia, el espíritu crítico- es totalmente vulnerable ante las acometidas de unas emociones que sean de signo contrario (2013, p. 78).

En la línea planteada por los autores arriba citados, la propuesta que se presenta persigue identificar aquellos usos, programas, redes y tecnologías que mejor se adecuan a los trabajos que los docentes deben encargar a sus estudiantes o desarrollar en las clases. No hay que olvidar que los resultados que arrojan las pruebas de Ser Maestro y Ser Bachiller en las zonas donde se ubican las escuelas denotan carencias en cuanto a los mínimos requeridos en las evaluaciones que se llevan a cabo. Es así, 
que hay que reforzar las competencias de los docentes en la alfabetización mediática que contemple la carga emocional que está implícita en los usos que los adolescentes hacen. Estos usos cada vez adquieren una mayor relevancia en los contenidos desplazando el rol de meros receptores a generadores de contenidos que se añaden a las narrativas, produciendo un universo transmedia, aunque solo sea incipiente en las escuelas analizadas.

Por último, como docentes hay que tener claro que se destina buena parte de la atención hacía las redes sociales de las celebridades que protagonizan las series y películas favoritas de estos adolescentes. Así, el culto a la fama y la identificación o idolatría que esas estrellas generan no es algo ajeno al comportamiento adolescente. Como bien indica Bajardi (2015) estos diferentes procesos de la evolución de la identidad se configuran a partir de elementos como identificación, individuación, imitación e internalización. Los cuales pueden servir de categorías de análisis que se incluyan en investigaciones posteriores.

\section{BIBLIOGRAFÍA}

Acaso, M. y Megías, C. (2017). Art Thinking. Barcelona: Paidós.

Aierbe-Barandiaran, A. y Oregui-González, E. (2016). Values and Emotions in Children's Audiovisual Fictional Narratives. [Valores y emociones en narraciones audiovisuales de ficción infantil]. Comunicar, 47, 69-77.

CML, Center for Media Literacy. Recuperado el 7 de agosto de 2018 de: http://www.medialit.org/sites/default/files/11_CMLEducPhil.pdf.

Almenara, J. C., y Cejudo, M. L. (2008). La alfabetización digital de los alumnos. Competencias digitales para el siglo XXI. Revista portuguesa de pedagogía, 7-28.

Aparici, R. y García Marín, D. (2017). Comunicar y educar en el mundo que viene. Barcelona: Gedisa.

Area, M. y Pessoa, T., (2012). De lo sólido a lo líquido: las nuevas alfabetizaciones ante os cambios culturales de la Web 2.0., Comunicar, 38, 13-20. 
Bajardi, A. (2015). La identidad personal en relación con la educación: características y formación del concepto. REiDoCrea. Revista Electrónica de Investigación y Docencia Creativa, 4,106-114.

Baudrillard, J. (1978). Cultura y simulacro. Barcelona: Kairós.

Benkler, Y., (2015), La riqueza de las redes. Cómo la producción social transforma los mercados y la libertad. Barcelona: Icaria Editorial.

Bolívar, A. (1997). La negociación de la evaluación en editoriales de periódicos. Boletín de Filología, 36, 7. Recuperado el 10 de septiembre de 2018 de: http://www.cuadernosjudaicos.cl/index.php/BDF/article/viewArticle/21479

Buckingham, D. (2005). Educación en medios. Alfabetización.

Christensen, C.M.; Johnson, C. \& Horn, M. (2008). Disrupting Class: How Disruptive Innovation Will Change the Way the World Learns. New York: McGraw-Hill Education. Damasio, A. (2006). El error de Descartes. Madrid: Crítica.

Ferrés i Prats, J. (2005). La familia frente al televisor: ¿víctima o culpable? En Revista Comunicar (25), 237-242.

Ferrés i Prats, J. (2007). La competencia en comunicación audiovisual: dimensiones e indicadores. Comunicar, 29, 100-107.

Ferrés, J. y Piscitelli, A. (2012). La competencia mediática: propuesta articulada de dimensiones e indicadores. Comunicar, 38, 75-82.

Ferrés, J., y Piscitelli, A. (2015). La competencia mediática: Propuesta articulada de dimensiones e indicadores. Revista Luciérnaga-Comunicación, 4(7), 72-79.

Fontcuberta, J. (2016), La furia de las imágenes. Barcelona: Galaxia Gutenberg.

Guitart, M. E. (2012). Del Homo intellectualis al Homo educandus La hipótesis de la inteligencia cultural y la intencionalidad compartida. Boletín de Psicología, (105), 2342. 
Gutiérrez Martín, A., y Tyner, K. (2012). Educación para los medios, alfabetización mediática y competencia digital. Comunicar, $n^{\circ} 38, v$. XIX, 31-39.

Jenkins H., Ford S. y Green J. (2015). Cultura Transmedia. La creación de contenido y valor en una cultura en red. Barcelona: Gedisa.

Jolls, T., \& Wilson, C. (2014). The core concepts: Fundamental to media literacy yesterday, today and tomorrow. Journal of Media Literacy Education, 6(2), 68-78.

Kaplan, N. (2004). Nuevos desarrollos en el estudio de la evaluación en el lenguaje: la teoría de la valoración. Boletín de Lingüística, 16(22), 52-78.

Kaplan, N. (2007). La construcción discursiva del evento conflictivo en las noticias por televisión. (Tesis de doctorado de la Universidad Central de Venezuela)

Levis, D. (2006). Alfabetos y saberes: la alfabetización digital. Comunicar, (26), 78-83.

Lévy, P. (1994). L'Intelligence collective. Pour une anthropologie du cyberespace. Paris. Éditions La Découverte.

Martin, J. R., \& White, P. R. (2005). The language of evaluation. Basingstoke and New York: Palgrave Macmillan. Recuperado el 4 de junio de 2018 de: http://saber.ucv.ve/ojs/index.php/rev bl/article/view/1468/1376

Reguillo, R. (2016). Epílogo en: Martín Barbero, J. Jóvenes. Entre el palimpsesto y el hipertexto, (pp. 217-221). Barcelona: Ned Ediciones.

Ribes, X. (2007). La Web 2.0. El valor de los metadatos y de la inteligencia colectiva. Telos, 73, 36-43.

Scolari, C. A. Winocur, R., Pereira, S. y Barreneche, C. (2018). Alfabetismo transmedia. Una introducción. Comunicación y Sociedad, 33, 7-13.

SENPLADES, Secretaría Nacional de Planificación y desarrollo. (2015). Agenda Zonal. ZONA 6 - Austro. Quito: Senplades. Recuperado el 8 de junio de 2018 de: http://www.planificacion.gob.ec/wp-content/uploads/downloads/2015/11/Agendazona-6.pdf 
SENPLADES, Secretaría Nacional de Planificación y desarrollo, Sistema Nacional de Información (SIN). (2017). Proyecciones y Estudios Demográficos. Recuperado el 8 de junio de 2018 de:http://sni.gob.ec/proyecciones-y-estudios-demograficos

Valero, F. G. (2004). La inteligencia compartida. Cuadernos de estrategia, (127), 151180. 